\title{
Microinjection of specific anti-IMPDH2 antibodies induces disassembly of cytoplasmic rods/rings that are primarily stationary and stable structures
}

\author{
Gerson Dierley Keppeke ${ }^{1,2}$, Luís Eduardo C Andrade ${ }^{2,3}$, Scott S Grieshaber ${ }^{4}$ and Edward K L Chan ${ }^{1 *}$
}

\begin{abstract}
Background: Our laboratory previously reported interesting rods 3-10 $\mu \mathrm{m}$ long and rings 2-5 $\mu \mathrm{m}$ diameter (RR) in the cytoplasm of mammalian cells. Experimental evidence show that both inosine-5'-monophosphate dehydrogenase 2 (IMPDH2) and cytidine triphosphate synthetase (CTPS) are components of RR structures. Several cell types, including mouse embryonic stem cells, and cell lines, such as mouse 3 T3 and rat NRK, naturally present RR structures, while other cells can present RR when treated with compounds interfering with GTP/CTP biosynthetic pathways. In this study, we aimed to investigate the dynamic behavior of these RR in live cells.
\end{abstract}

Results: RR were detected in $>90 \%$ of COS-7 and HeLa cells treated with $1 \mathrm{mM}$ ribavirin or 6-Diazo-5-oxo-L-norleucine (DON) for $24 \mathrm{~h}$, and in 75\% of COS-7 cells treated with $1 \mathrm{mM}$ mycophenolic acid (MPA) for the same period of time. Microinjection of affinity-purified anti-IMPDH2 antibodies in live COS-7 cells treated with ribavirin, DON, or MPA showed mature forms of RR presented as stable and stationary structures in $71 \%$ of cells. In the remaining $29 \%$ of cells, RR acquired erratic movement and progressively disassembled into fragments and disappeared within $10 \mathrm{~min}$. The specific stationary state and antibody-dependent disassembling of RR structures was independently confirmed in COS-7 and HeLa cells transfected with GFP-tagged IMPDH2.

Conclusions: This is the first demonstration of disassembly of RR structures upon microinjection of anti-IMPDH2 antibodies that led to the disappearance of the molecular aggregates. The disassembly of RR after microinjection of anti-IMPDH2 antibody further strengthens the notion that IMPDH2 are major building blocks of RR. Using two independent methods, this study demonstrated that the induced RR are primarily stationary structures in live cells and that IMPDH2 is a key component of RR.

Keywords: CTP synthase, Cytoophidium, Inosine monophosphate dehydrogenase, Intracellular compartment, Mycophenolic acid, Ribavirin

\section{Introduction}

Unique intracellular rods $3-10 \mu \mathrm{m}$ long and rings $2-5 \mu \mathrm{m}$ diameter (RR) have been characterized in the cytoplasm of many cell types [1-4]. Experimental evidence indicates that inosine-5'-monophosphate dehydrogenase 2 (IMPDH2) is a major component of the RR structures, but cytidine triphosphate synthetase (CTPS), another enzyme involved in nucleotide metabolism, has also been shown to be part of RR structures [2,4,5]. A recent review article has highlighted that many metabolic enzymes

\footnotetext{
*Correspondence: echan@ufl.edu

'Department of Oral Biology, University of Florida, 1395 Center Drive,

Gainesville, FL 32610-0424, USA

Full list of author information is available at the end of the article
}

aggregate and form similar large fibers or intracellular bodies across the diverse organisms [6]. Although it is not yet clear whether all aggregates represent functional entities or storage bodies, examples of assembled fibers are discussed as a result of pathological damage in the enzymes (e.g. sickle-cell hemoglobin), enhance enzymatic activity (e.g. acetyl-CoA carboxylase), structural elements (e.g. actin fibers and microtubules), and to provide storage catalytic potential (e.g. CTPS) [6]. Three very recent reports show apparently contradicting conclusions regarding the enzymatic state of the CTPS enzyme when presented in these filamentary RR form. Barry et al. [7] concluded that the formation of RR in E. coli inhibits the activity of the CTPS enzyme and Aughey et al. [8] found similarly 
inhibited CTPS activity in RR in Drosophila tissues. However, Strochlic et al. [9] demonstrated that the CTPS within the RR structures in Drosophila are catalytically active. Thus the current hypotheses are that the assembly and disassembly of RR represent highly sensitive control of enzymatic activities by keeping enzymes in active/inactive forms and this can be an important mechanism of regulation of the indispensable GTP/CTP synthesis pathway within the cell. It should be noted that CTPS and IMPDH are rate-limited enzyme in de novo cytosine and guanine nucleotide biosynthesis, respectively.

Several cell lines naturally present RR structures including mouse 3 T3, rat NRK, and rat kangoroo Ptk2, as well as mouse embryonic stem cells [1], but for many other cancer cell lines grown in vitro, RR structures are usually not detected under normal culture conditions. However, in all cell lines treated to date with compounds interfering with GTP and CTP biosynthetic pathways, abundant RR structures are readily detected within minutes to hours [1]. For example, ribavirin and DON that inhibit IMPDH2 and CTPS, respectively, are highly capable of inducing RR structures that are readily observed with indirect immunofluorescence using antibodies to IMPDH2 or antibodies from patients with chronic hepatitis $\mathrm{C}$ viral $(\mathrm{HCV})$ infection under treatment with ribavirin and interferon- $\alpha$ [2,10-14]. In fact, it has been shown that HCV patients treated with IFN- $\alpha$ and ribavirin develop autoantibodies against $R R$ after the sixth month of treatment, with titers increasing throughout treatment, and eventually decreasing after treatment interruption [11]. These autoantibodies seem to be, in most cases, directed against IMPDH2, which intriguingly is the prime target of ribavirin used in anti-HCV treatment in these patients $[2,10,15]$.

The study of live cells has been critical for the elucidation of many cellular functions as well as dynamic interactions between organelles and other cell domains. An emblematic example is the characterization of intracellular cargo transport on microtubules. Live cell observations of microtubule vesicle transport revealed regulation of the polarity of trafficking and the roles of kinesins and dynein in the transport of cargo as well as a better understanding of the processes that regulate the behavior of transport at microtubule intersections [16-19]. Transfection of genes with fluorescent tags is a common method to label proteins for live cell investigation [20,21]. This technique allows the study of the dynamic movement of a given protein or subcellular structure. This approach facilitates the real-time longitudinal observation of the target antigens in live cells subjected to a diverse array of in vitro conditions [22]. Transfection of an IMPDH2-GFP fusion construct, by Thomas et al. [3], to examine the aggregation of IMPDH2 into RR structures found diffuse cytoplasmic distribution of spicules that, by end-to-end or side-by-side fusions, clustered into macrostructures; for these experiments, only low expressing IMPDH2-GFP transfected cells were first sorted and examined as apparently high expressing cells failed to form RR-like structures. The latter is consistent with the report of Carcamo et al. [2] that high expression of IMPDH2-GFP in transfected cells inhibited the formation of RR structures, even when treated with ribavirin. Thus the expression levels of IMPDH2 affects the assembly of RR and this is largely consistent with the above discussion that linking these structures to the functional levels of the associated enzymes.

Another approach to study the behavior of biomolecules in live cells is the microinjection of fluorescentlabeled antibodies. The study of cellular structures in the presence of antibodies targeting their protein components can provide important information about intrinsic characteristics of the structure of interest [23-25]. For example, the microinjection of monoclonal antibodies to intermediate filaments into fibroblast cell lines causes them to break down into numerous small spheroid aggregates scattered throughout the cytoplasm [26,27]. In fact, microinjection of antibodies against different cytoskeletal proteins was a fundamental approach in unveiling the ultrastructure, intermolecular relationships, and several functional aspects of important cell structures, especially intermediate filaments, in different tissues and cell lines.

The recently reported cytoplasmic RR structures are still poorly characterized. In this study, we aimed to investigate the spatial relationships of the RR structures over time in live cells as well as the behavior of these structures by antibody microinjection analysis.

\section{Results}

Since COS-7 cells have been used extensively for livecell imaging techniques, including microinjection, it was practical to adapt this system to analyze RR function. The first experiment was to validate if ribavirin-treated COS-7 cells were capable of RR formation. Human prototype anti-RR serum and rabbit polyclonal anti-IMPDH2 antibody were shown to recognize the characteristic set of RR structures in ribavirin-treated COS-7 cells (Figure 1A-C). The same was true in COS-7 cells treated with DON (Figure 1D) or MPA (Figure 1E). However, RR were not detected in untreated COS-7 cells as expected (Figure 1G). When the effect of the concentration of ribavirin was examined, the percentage of COS-7 cells presenting RR structures increased with the concentration of the drug. At $0.5 \mu \mathrm{M}$ ribavirin, $39 \%$ of cells presented RR, and at 1 and $2 \mathrm{mM}, 95 \%$ of cells presented the RR structures (Figure $1 \mathrm{H}$ ). Most treated COS-7 cells presented only one RR structure per cell (Figure 1A-E). In contrast, more than $80 \%$ of HeLa cells treated with $1 \mathrm{mM}$ ribavirin 


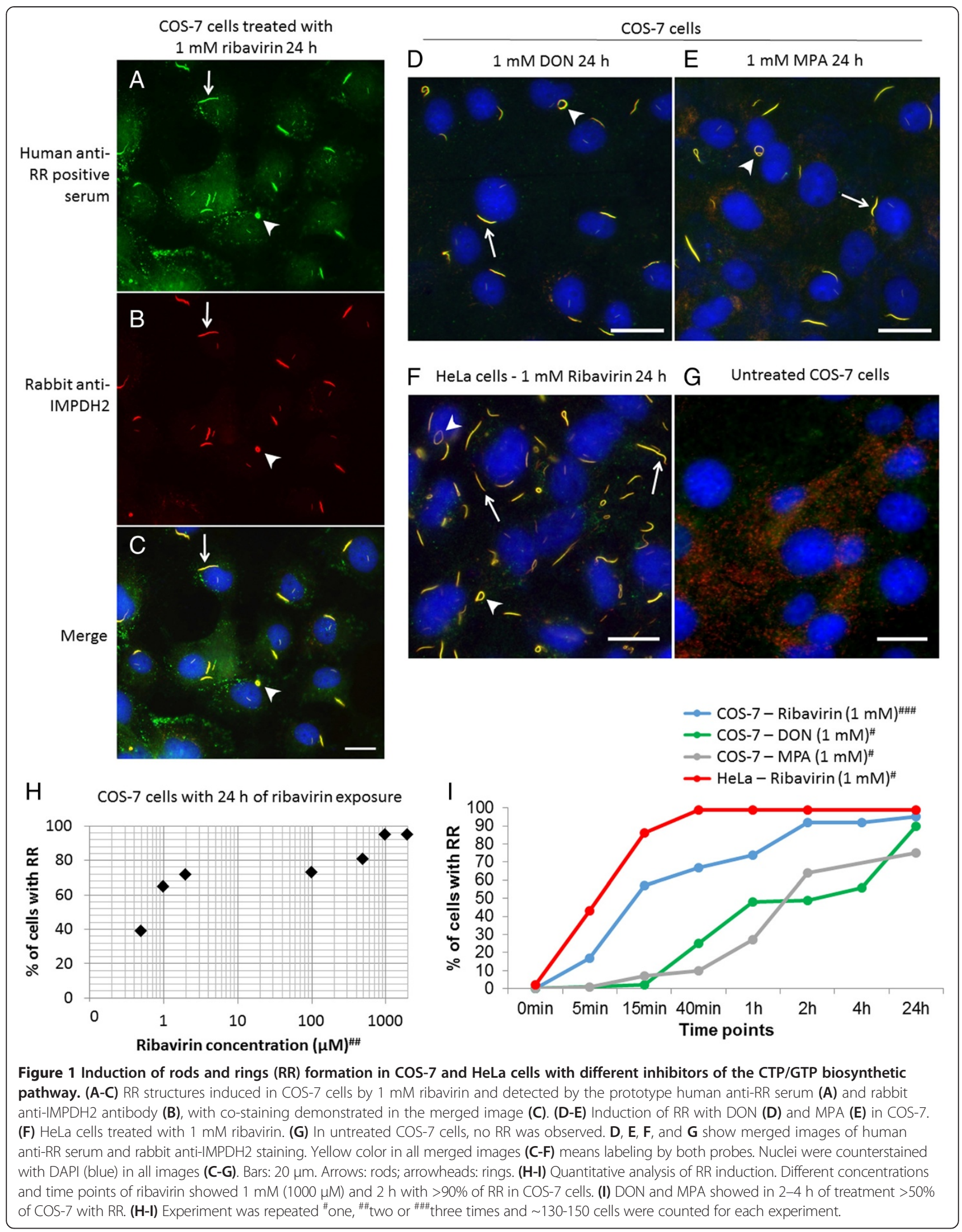


for $24 \mathrm{~h}$ presented four or more RR structures (42 cells examined; Figure 1F).

In order to design the optimal live-cell imaging experiment for RR using COS-7 cells, it was necessary to determine how long it would take for RR to appear after treatment with various RR-inducing compounds. Timelag experiments in COS-7 cells over a $24 \mathrm{~h}$ period were performed with $1 \mathrm{mM}$ ribavirin, DON, or MPA, and RR structures were detected in $95 \%, 90 \%$, and $75 \%$ of the treated cells, respectively (Figure 1I). About $50 \%$ of COS-7 cells were observed with RR structures after 15 min of ribavirin treatment. The induction of $R R$ assembly with $1 \mathrm{mM}$ DON or MPA was slower than that of $1 \mathrm{mM}$ ribavirin. In contrast, HeLa cells demonstrated faster kinetics compared to COS-7 cells in RR assembly induced by $1 \mathrm{mM}$ ribavirin and only $40 \mathrm{~min}$ exposure was sufficient to induce RR structures in $100 \%$ of the cells (Figure 1I).

The initial strategy was to microinject fluorescenttagged anti-IMPDH2 antibodies into live COS-7 cells in order to follow the dynamics of RR. The rabbit antiIMPDH2 antibody used is highly specific because it was an antigen-affinity purified preparation and showed only a single $55 \mathrm{kDa}$ IMPDH2 band in immunoprecipitation analysis [2,28]. To demonstrate that the chemically conjugated anti-IMPDH2 antibodies remained functionally intact, direct immunofluorescence with Alexa 488conjugated rabbit anti-IMPDH2 antibody was performed in COS-7 cells treated with $0.1 \mathrm{mM}$ ribavirin for $24 \mathrm{~h}$. Out of 171 cells analyzed, 73\% showed RR structures, indicating that the Alexa 488-conjugated rabbit anti-IMPDH2 antibody appeared to retain sufficient reactivity for our intended experiment (Additional file 1: Figure S1). In addition, we further investigated whether the various experimental conditions required for the microinjection setting could affect the assembly and disassembly of RR structures. After $24 \mathrm{~h}$ of treatment with $0.1 \mathrm{mM}$ ribavirin, COS-7 cells were incubated for $2 \mathrm{~h}$ with the microinjection buffer, Hank's medium, or DNA dye Draq5. In all these required microinjection conditions examined, the ribavirin-treated cells continued to show the RR structures comparable to cells not exposed to such reagents (Additional file 1: Figure S2).

Microinjection of Alexa 488-conjugated rabbit antiIMPDH2 antibodies in COS-7 cells showed that druginduced RR maintained as intact, stable, and stationary structures, i. e., there was no significant movement or changes in size and shape of RR in the majority of cells $(71 \%$ out of 263 cells counted), however in the remaining 29\% of the cells RR structures disassembled. These stable and stationary effects were observed in cells 10 min after microinjection regardless of the drug treatment used ( $1 \mathrm{mM}$ ribavirin, DON, or MPA for $24 \mathrm{~h}$ ); images were captured at $2 \mathrm{~min}$ intervals for an additional $10 \mathrm{~min}$, indicating no change over time independent of the type of drug used
(Figure 2). In most cases, the cytoplasmic RR structures did not show relevant changes in shape or size, even in video images captured at 10-second intervals for $10 \mathrm{mi}$ nutes (Additional file 2: Movie S1). The same was observed when cells were followed for a longer time up to 30 min (Figure 2D). In 76 (29\%) of the 263 COS-7 cells that received microinjection, RR structures were observed disassembling into fragments and eventually disappeared, independent of which drug was used to induce RR (Figure 3). Images were captured at 10-second intervals to observe the disassembly and erratic movements of ribavirin-induced RR (Additional file 3: Movie S2) and MPA-induced RR (Additional file 4: Movie S3). As a control, we compared the influence of microinjection of antiIMPDH2 antibody versus total rabbit IgG in a slide area with $\sim 200$ COS-7 cells (Figure 3D, E and F). The fraction of cells presenting RR was much less in the area microinjected with anti-IMPDH2 antibody (38\%; total = 91) compared to those in the same slide microinjected with control total rabbit IgG $(84 \%$; total $=95)(p=0.0001$ by Two-tailed Chi-square test). In the same slide, the fraction of cells without microinjection bearing RR was 95\% (total $=103$, Figure $3 G$ ). To determine whether the disassembly of RR was dependent on the amount of anti-IMDPH2 antibody microinjected, COS-7 cells were microinjected for either $0.2 \mathrm{~s}$ each $(\sim 8,000$ antibody molecules) or $2 \mathrm{~s}$ each ( 80,000 antibody molecules). Disassembly of RR was observed in $13 \%$ of cells with 0.2 -s microinjection versus $48 \%$ in cells with 2-s microinjection 20 min later (Additional file 1: Figure S3). This data suggest that the disassembly of some induced RR was mediated by the higher level of microinjected anti-IMPDH2 antibody in those cells (see below) while in cells microinjected with low level of antibody, the antibody served mainly to label $\mathrm{RR}$ and demonstrating their stationary state.

To obtain independent support for the results of the microinjection experiment above, transfection of an IMPDH2GFP fusion construct was performed to rule out effects that might be from the interference of antibody microinjection. In transfected COS-7 cells treated with $1 \mathrm{mM}$ ribavirin for $18 \mathrm{~h}, \mathrm{RR}$ structures were also observed to be stable and stationary, showing no changes in shape and size within a 10 min interval (Figure 4A). The same was true when images were captured at 30 second intervals for $10 \mathrm{~min}$ (Additional file 5: Movie S4). In this same experiment, similarly transfected cells were also examined by IIF with anti-IMPDH2 (Figure 4B). Transfected cells (arrows and arrowheads, left panel) showed two distinct phenotypes. Interestingly, cells with very high transfection levels (arrows), gauged by high diffuse cytoplasmic GFP fluorescence (left panel), did not show RR structures, even when labeled by anti-IMPDH2 (arrows). The second type of transfected cells (arrowheads) with relatively low expression of IMPDH2GFP showed distinct RR structures (left panel) that are also 


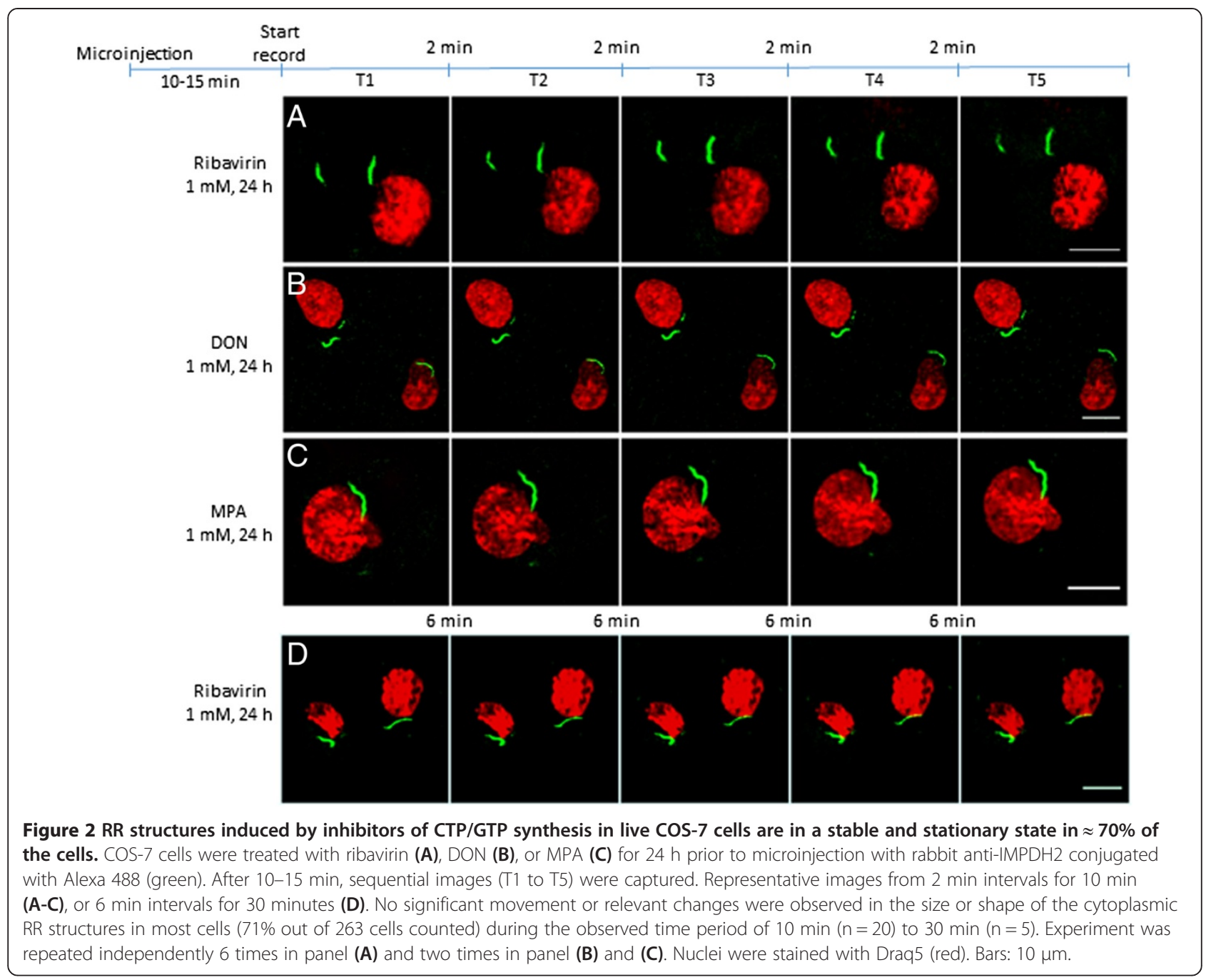

labeled by anti-IMPDH2 antibody (mid and right panels). No relevant diffuse cytoplasmic fluorescence is observed in these cells. Non-transfected cells show typical RR recognized by anti-IMPDH2 (double arrows).

COS-7 cells were used in the present study due to the increased thickness of these cells, which facilitates the procedures of microinjection. However, all experiments were also performed independently in HeLa cells to validate that the present observation was not limited to COS-7 cells. The follow-up for $10 \mathrm{~min}$ after microinjection of HeLa cells (24 h after treatment with $1 \mathrm{mM}$ ribavirin) also showed stationary RR structures, with no changes in shape and size (Additional file 1: Figure S4A). No changes in size or shape of RR structures were observed in HeLa cells labeled by transfected IMPDH2GFP (Additional file 1: Figure S4B), similar to COS-7 cells. The GFP-tagged RR structures in transfected HeLa cells, as in COS-7 cells, were also recognized by anti-IMPDH2 in IIF (arrow, Additional file 1: Figure $\mathrm{S} 4 \mathrm{C})$.

\section{Discussion}

Our overall data showed that RR were stationary and stable structures in imaged live cells. This means cell maintained intact RR structure with no change in size and shape (stable) and showed no significant movement (stationary). During independent observation of live cells transfected with GFP-tagged IMPDH2, RR also appeared stationary and stable in size and shape.

In our previous study, RR were induced by ribavirin, MPA, and DON, that inhibit enzymes involved in the biosynthetic pathway of guanosine triphosphate (GTP) and cytidine triphosphate (CTP) [1,2]. In this work, RR structures were examined by induction with ribavirin and MPA, which inhibited the IMPDH2 enzyme in an irreversible and reversible manner, respectively. RR structures induced by DON, which inhibits the enzyme CTPS in the CTP biosynthetic pathway, were also recognized by anti-IMPDH2 antibody. In experiments with COS-7 cells, ribavirin induced a higher percentage of cells to form $\mathrm{RR}$ and at a faster rate compared to those induced 


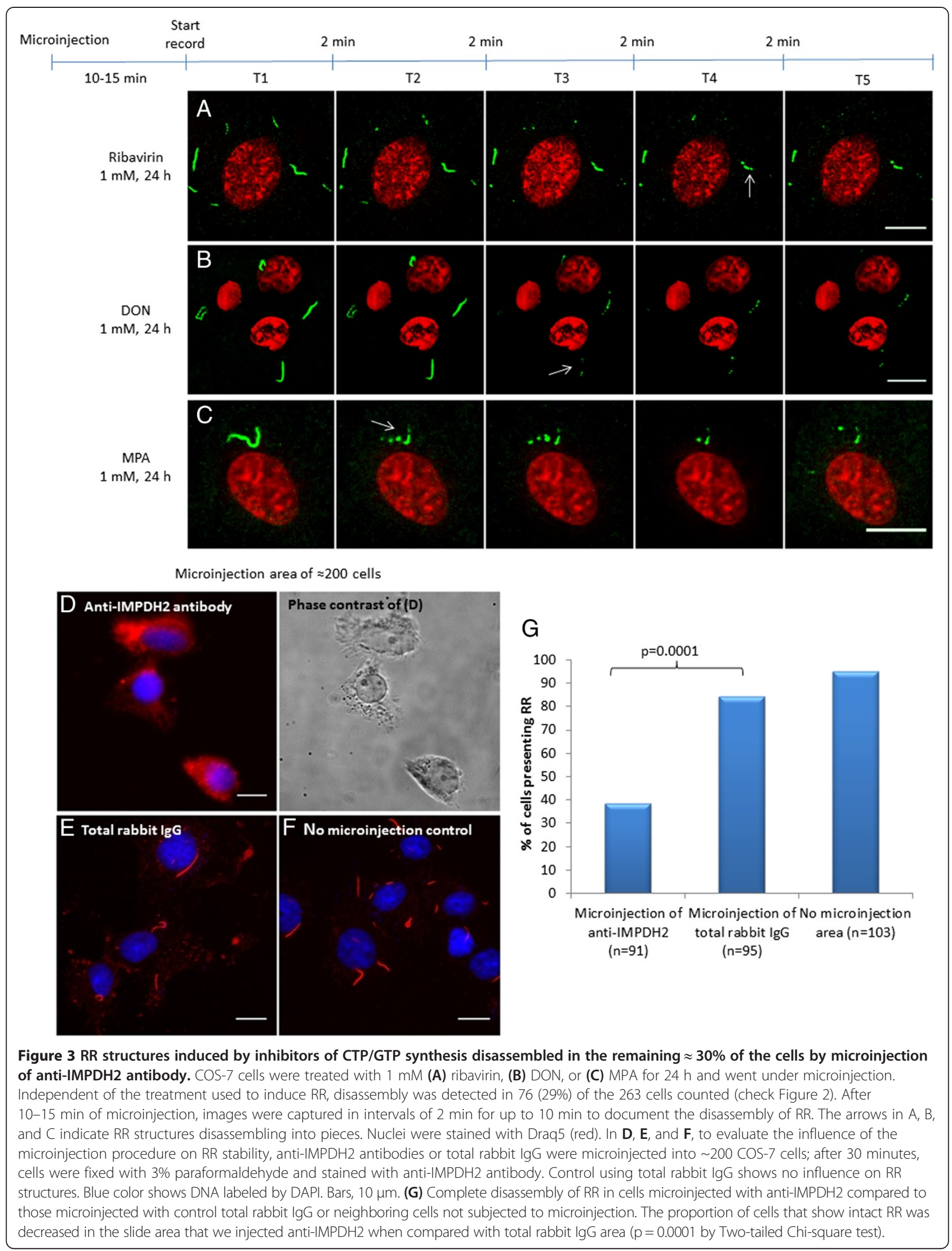




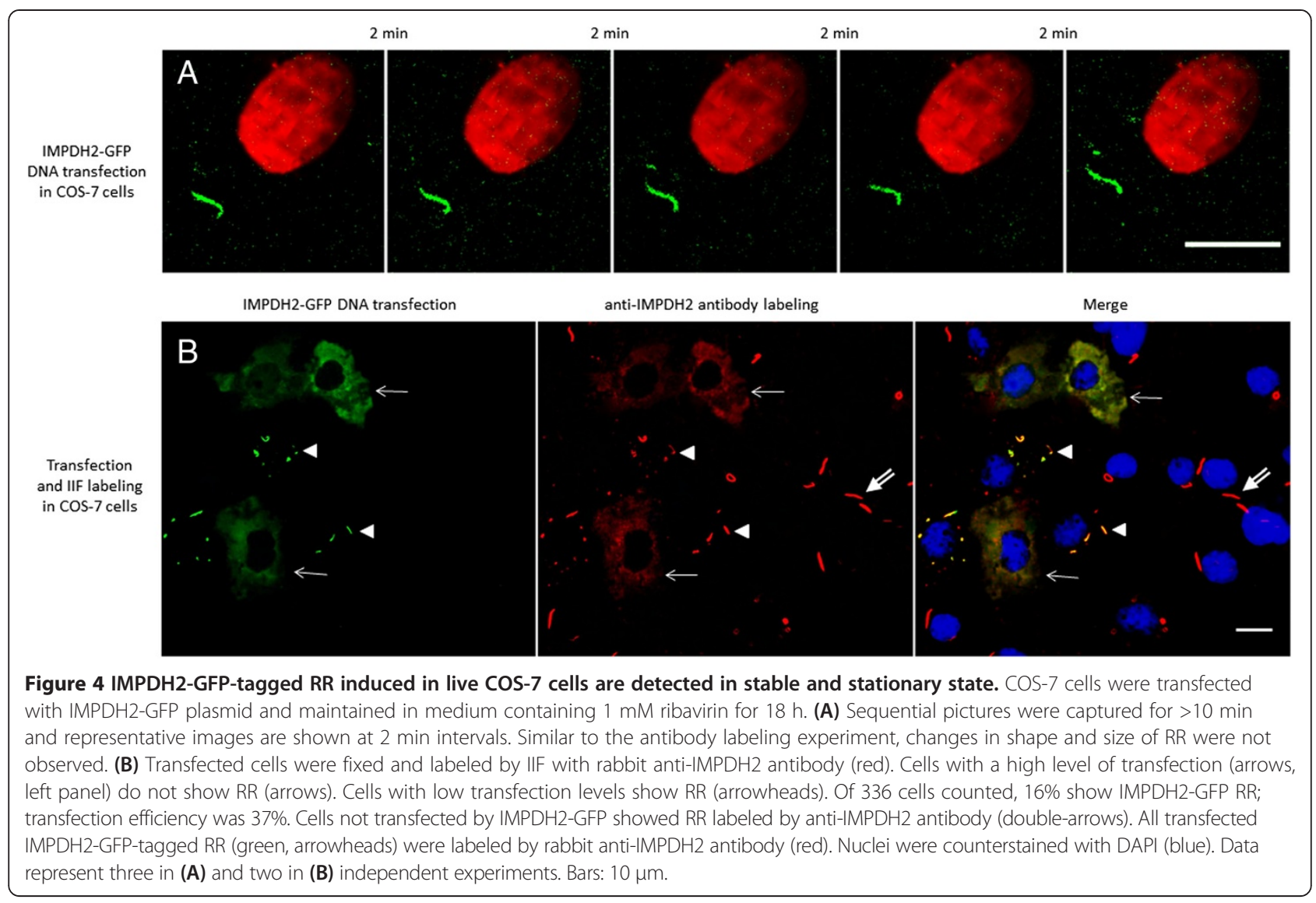

with MPA or DON at the same concentration. This observation was consistent with our reported in the induction of RR in HEp-2 cells [2]. In this study, under all conditions of RR induction, similar results were observed where most structures appeared stable and stationary ( $\sim 70 \%$ of cells).

HeLa cells had a higher number of RR structures per cell than COS-7 cells (average $\geq 4$ versus 1 ) and faster kinetics in RR assembly; in just 40 minutes of treatment with ribavirin, $100 \%$ of HeLa cells already presented RR, in contrast to $67 \%$ of COS-7 cells. This observation may be related to the amount of IMPDH2 enzyme available, which is influenced by the necessary IMPDH2 enzymatic activity for each cell line $[29,30]$. The amount of IMPDH2 is also influenced by cellular nucleotide pools, which are related to cellular activities like mitosis and protein synthesis [31,32]. We reported recently that glutamine deprivation for $72 \mathrm{~h}$ induced RR assembly in HeLa cells (purine and pyrimidine pathways are highly glutaminedependent), and the RR structures disappeared within 15 min of adding $1 \mathrm{mM}$ guanosine to the culture medium [33]. The higher frequency and faster kinetics of RR formation in HeLa compared to COS-7 cells could be based on other differences between these cell types, as COS-7 is originated from green monkey kidney while
HeLa is from a human cervical cancer, and previous reports shows higher expression of IMPDH2 in cancer cells $[34,35]$. Our data demonstrated that these cell types have different sensitivity to the induction of $R R$ formation in the presence of different RR-inducing drugs. This in part might also be related to their difference in mitotic activity. In our experience, HeLa cells grow to confluence twice as fast as COS-7 cells.

Our study focused on the stationary and stable RR in live cells during the $30 \mathrm{~min}$ observation period. Other studies have examined the assembly process of RR. Gou et al. [36] explored the formation of cytoophidia (Greek for "cellular snakes", another name used to described RRlike structures) by CTPS-GFP transfection into mouse $\mathrm{NIH} / 3 \mathrm{~T} 3$ cells treated with DON $(50 \mu \mathrm{g} / \mathrm{ml})$ for $10 \mathrm{~min}$ prior to recording live cell images. They showed small aggregates with dynamic movements forward and backward, and sometimes movement toward each other with end-toend fusions to increase the length or side-by-side to increase thickness of the structures [36]. Another study by Thomas et al. [3] reported the clustering of GFP-tagged IMPDH2 in live HeLa cells treated with $2 \mu \mathrm{M}$ MPA just before recording images and they also found diffuse cytoplasmic distribution of spicules that, by end-to-end or side-by-side fusions, clustered into macrostructures. In 
our experiments, the cells were exposed to the CTP/GTP pathway inhibitor drugs for much longer times, $24 \mathrm{~h}$ prior to anti-IMPDH2 microinjection and $18 \mathrm{~h}$ prior to recording in IMPDH2-GFP-transfected cells. The RR structures that we observed were already fully developed and mature, leading to the observed stationary and stable status. This explains why we did not capture any "pre-aggregation" changes (increase in thickness and length) in the short period of time that we recorded the structures; preaggregation changes in size and shape previously observed by others are probably related to the assembly process of RR.

The presence of the RR structure may explain some undescribed correlations between the loss of tolerance and autoantibody production in $\mathrm{HCV}$ patients treated with interferon/ribavirin [11,12,14,28]. In fact, unpublished observations from our laboratory show that RR structures are present in the cytoplasm of peripheral blood mononuclear cells of HCV patients treated with ribavirin (manuscript in preparation). In this study, we observed that mature RR structures are primarily stable and stationary in live cells when followed for a short period of time. A limitation of this study, however, is that we only followed the cells for up to $30 \mathrm{~min}$. Further studies are needed to determine why the IMPDH2 enzymes are clustering into RR under enzyme inhibition or nucleotide pool alterations. This will help to understand the function of cellular RR structures and why treated HCV patients produce anti-IMPDH2 autoantibodies.

We observed that microinjection of anti-IMPDH2 antibodies caused disassembling of RR structures in approximately $29 \%$ of COS-7 cells. Structures that disassemble in the presence of antibodies targeting themselves have been demonstrated before. Components of cytoskeletal intermediate filaments, in the presence of antibodies targeting specific structures, tend to be disassembled into cytoplasmic foci or clumps. For example, the microinjection of monoclonal antibodies to intermediate filaments into fibroblast cell lines caused these filaments to break down into numerous small spheroid aggregates scattered throughout the cytoplasm $[26,27,37]$. In a study of the Golgi complex, microinjection of anti-dynein heavy chain antibodies was shown to disperse the Golgi complex in about $50 \%$ of NRK cells, suggesting that the dynein motor is involved in establishing proper Golgi organization [38,39]. The disassembling of RR structures in the presence of an anti-IMPDH2 antibody strongly indicates that IMPDH2 enzyme is an important element in RR, analogous to the demonstration of dynein as the motor in Golgi organization.

The disassembly of the RR structures after microinjection of anti-IMPDH2 antibody could be due to the steric hindrance generated by IMPDH2 epitope-paratope interaction, which potentially interferes with the aggregation or polymerization process of RR. In a parallel situation, the microinjection of antibodies targeting intermediate filaments, that cause them to break down into small spheroid aggregates, has been interpreted as the antibody physically blocking the region of the intermediate filaments that reacts with a cellular component which normally causes them to stretch out [37]. Antibody microinjection is a useful tool to study enzymatic activity because the antibody may block the enzyme activity in vivo [40]. In the case of RR structures, the IMPDH2 enzyme is already blocked by ribavirin and MPA treatment. In addition, the used anti-IMPDH 2 antibodies are not known be able to block the enzyme activity.

An interesting point is that disassembly of RR structures was observed in only a fraction of the microinjected cells varying slightly from experiment to experiment. This may be due to the variability in the amount of the antibody microinjected, a methodological variable that is difficult to control completely [41,42]. According to the Avogadro's law $\left(6.02 \times 10^{23}\right.$ molecules/mole), the number of antibody molecules microinjected into each cell was calculated to be 4,000 to 40,000 molecules, taking into consideration the time duration of microinjection in each cell ( $0.1 \mathrm{~s} \approx 4,000$ molecules). When COS-7 cells were microinjected for either $0.2 \mathrm{~s}$ each or $2 \mathrm{~s}$ each, the data supports a relationship that larger amount of antibody microinjected is correlated with the increase in the percent of cells showing disassembly of RR. This relationship allows for two possibilities within the cell: (1) a high level of injected antibody allows for increased binding to the RR structure, leading to a high rate of disassembly, or (2) low levels of injected antibody are not enough to significantly disturb the aggregation/polymerization process or potential activity of the RR structure, enabling us to follow the structure for a short time (10 to $30 \mathrm{~min}$ ) without visualizing considerable alterations in shape or size.

In conclusion, we show for the first time the disassembly of RR structures in the presence of an antibody targeting IMPDH2, a molecular constituent of RR. By two independent methods, induced RR are demonstrated to be primarily stable and stationary structures in live cells. The disassembly of the RR structures in some cells after microinjection of anti-IMPDH2 antibody further strengthens the notion that IMPDH2 molecules are major building blocks of RR. Further studies exploring the chemical interaction among IMPDH2 molecules in the assembly of RR may provide a full understanding of how the RR structures are assembled in cell cytoplasm. However, it is acknowledged that our conclusion with induced RR, without further experiments, may not be generalized to naturally observed RR such as those in mouse embryonic stem cells, mouse $3 \mathrm{~T} 3$, or rat NRK cells.

\section{Materials and methods}

\section{Cell culture and drug treatment}

COS-7 cells from green monkey kidney and HeLa cells from human cervical cancer were obtained from the 
American Tissue Culture Collection (Manassas, VA) and cultured in 8-well Culture Slides (BD Falcon ${ }^{\mathrm{Tm}}$; CA, USA) for transfection, drug treatment, and immunofluorescence (IIF) analyses. Alternatively, these cells were cultured on round $22 \mathrm{~mm}$-diameter coverslips for microinjection procedures. Both cell lines were cultured in Dulbecco's Modified Eagle Medium (DMEM) with 10\% Fetal Calf Serum (FCS) at $37^{\circ} \mathrm{C}$ and $5 \% \mathrm{CO}_{2}$. Adherent cell lines were maintained at $50 \%$ confluence.

COS-7 and HeLa cells were treated with compounds reported to induce RR structures [2,12]. Ribavirin (SigmaAldrich; R9644,) and mycophenolic acid (MPA, SigmaAldrich; M3536) were solubilized in tissue culture grade water to a $50 \mathrm{mM}$ stock and 6-diazo-5-oxo-Lnorleucine (DON, Sigma-Aldrich; D2141) was solubilized in water to a $100 \mathrm{mM}$ stock and stored at $-80^{\circ} \mathrm{C}$ until use. Drugs at various concentrations were added to cell culture $24 \mathrm{~h}$ prior to fixation.

\section{IIF procedure}

Cells were fixed with $3 \%$ paraformaldehyde in PBS for $10 \mathrm{~min}$, followed by permeabilization with $0.1 \%$ tritonX100/PBS for 5 min $[43,44]$. For co-staining studies, cells were incubated for $1 \mathrm{~h}$ simultaneously with antigen-affinity purified rabbit anti-IMPDH2 polyclonal antibody (ProteinTech; 12948-1-AP) diluted $1 / 500$ in PBS and human prototype anti-RR positive serum It2006 [2] also diluted $1 / 500$ in PBS. Secondary antibodies were goat anti-rabbit IgG conjugated to Alexa Fluor 568 (Molecular Probes; A11036) and goat anti-human IgG conjugated to DyLight 488 (KLP- Kirkegaard \& Perry Laboratories; 072-03-10-06), both diluted $1 / 500$ in PBS. Secondary antibodies were also incubated simultaneously for $40 \mathrm{~min}$. The entire IIF procedure was performed at room temperature in a wet chamber in the dark. Slides were sealed with VECTASHIELD ${ }^{\circ}$ Mounting Medium with DAPI (VECTOR Labs, CA, USA) and analyzed at $\times 400$ magnification with fluorescence microscopy system (Carl Zeiss, Germany).

Rabbit anti-IMPDH2 antibody $(0.26 \mu \mathrm{g} / \mu \mathrm{L})$ was concentrated 5-6 fold using Amicon Ultrafilters (30-kDa cutoff, Millipore; UFC503008) according to the manufacturer's recommended procedure. Labeling of the concentrated anti-IMPDH2 antibody was performed according to manufacturer recommendation using the Alexa Fluor ${ }^{\oplus}$ 488 Microscale Protein Labeling Kit (Molecular Probes; $\mathrm{A}-30006)$. The labeled antibody was resuspended in microinjection buffer $\left(48 \mathrm{mM} \mathrm{K} \mathrm{HPO}_{4}, 14 \mathrm{mM} \mathrm{NaH} \mathrm{PO}_{4}\right.$, $4.5 \mathrm{mM} \mathrm{KH}_{2} \mathrm{PO}_{4}, \mathrm{pH} 7.2$, sterilized by $0.22 \mu \mathrm{m}$ filtering) and tested for activity in a direct fluorescence assay (diluted 1/300 and incubated $30 \mathrm{~min}$ ) with COS-7 cells treated with $0.1 \mathrm{mM}$ ribavirin for $24 \mathrm{~h}$ (Additional file 1: Figure S1). Despite the pre-labeling concentration process, the final concentration of labeled antibody determined by NanoDrop-1000 was $0.17 \mathrm{ng} / \mathrm{nl}$.

\section{Microinjection of anti-IMPDH2}

COS-7 and HeLa cells cultured on round coverslips were treated with ribavirin, DON, or MPA for $24 \mathrm{~h}$ to induce the formation of $\mathrm{RR}$ as previously described [2] prior to microinjection of anti-IMPDH2 antibody. Coverslips were transferred to the microscopy coverslips support (Leica DMIRB; Germany) with temperature control at $37^{\circ} \mathrm{C}$, immersed in Hank's medium (5.33 mM $\mathrm{KCl}, 0.44 \mathrm{mM} \mathrm{KH_{2 }} \mathrm{PO}_{4}, 138 \mathrm{mM} \mathrm{NaCl}, 4 \mathrm{mM} \mathrm{NaHCO}$, $0.3 \mathrm{mM} \mathrm{Na}_{2} \mathrm{HPO}_{4}, 5.6 \mathrm{mM}$ D-glucose, $\mathrm{pH}$ 7.2, sterilized by $0.22 \mu \mathrm{m}$ filtering and added 1:100 antibiotics Penicillin 10,000 U/mL and Streptomycin 10,000 $\mu \mathrm{g} / \mathrm{mL}$ ). Microinjection of the antibody was performed by FemtoJet ${ }^{\circ}$ System (Eppendorf). Femtotips needles (Type I, $1.0 \mu \mathrm{m}$, Eppendorf; 930000035) were loaded with 1-2 $\mu \mathrm{L}$ of either the Alexa Fluor 488-conjugated rabbit antiIMPDH2 $(0.17 \mathrm{ng} / \mathrm{nL})$ or control rabbit total IgG. Microinjection was performed on average 4-6 microscopic fields at $1000 \times$ magnification $(\sim 100$ cells $)$. Pressure of injection was set at 2.0 to 3.0 psi and injection time between 0.1 to 1 second. Then, 3-5 cells were randomly chosen to be followed by confocal microscopy (Yokogawa QLC-100; AIC, New Jersey) and images captured with a camera (Cascade II: 512; Photometrics ${ }^{\oplus}$ ), both attached to the microscope. Nuclei were visualized by staining with $5 \mu \mathrm{M}$ Draq5 (BioStatus, United Kingdom; DR50050) added to the culture medium. Sliced images were captured for each chosen cell in 10-30 second intervals for 10 to 30 minutes.

\section{Transfection of IMPDH2-GFP}

COS-7 and HeLa cells were seeded in 8-well chambers at $50-70 \%$ confluency $\left(5 \times 10^{4}\right.$ cells/well $)$ overnight prior to transfection. Cells were transfected with $0.24 \mathrm{ng} / \mu \mathrm{L}$ of IMPDH2-GFP DNA, cloned in the pCMV6-AC-GFP vector driven by the human cytomegalovirus (CMV) promoter (OriGene, Rockville, MD; RG202977), diluted in OPTi-MEM (Gibco, Cat.:31985-070), using Lipofectamine 2000 (Invitrogen, Cat.:11668-019) mixture at 1:1 ratio, and incubated for $6 \mathrm{~h}$. After incubation, DMEM without antibiotics plus RR-inducing drug was added for 15-18 h. Transfection efficiency was $25-40 \%$. The transfected cells were analyzed after fixation by IIF or directly as live cells using confocal microscopy. Sliced images were captured for randomly chosen cells in 30 second intervals for up to 10 minutes.

\section{Image analysis}

Image sequences from confocal microscopy and IIF images were analyzed with OMERO.insight 4.4 and ImageJ $1.47 \mathrm{~m}$ with LOCI and Fiji plugins for Windows. Cells with or without RR structures were counted in captured images with ImageJ Analyze Particles tool, or by eye in randomly chosen microscopic fields. Statistical significance was 
determined with GraphPad Prism v5.0 using Two-tailed Chi-square test and $\mathrm{p}<0.05$ was considered significant.

\section{Additional files}

Additional file 1: Figure S1. Direct immunofluorescence of ribavirininduced RR in COS-7 cells with rabbit anti-IMPDH2 conjugated with Alexa 488 (green). COS-7 cells treated with $0.1 \mathrm{mM}$ ribavirin for $24 \mathrm{~h}$ were fixed and stained with Alexa 488-conjugated rabbit anti-IMPDH2 at 1:300 dilution for $30 \mathrm{~min}$. Of 171 cells counted, 73\% showed RR. Nuclei were counterstained by DAPI (blue). Bar: 20 um. Figure S2. No observed changes in RR structures under various conditions used in our typical microinjection assay. COS-7 cells were treated with $0.1 \mathrm{mM}$ ribavirin for $24 \mathrm{~h}(\mathrm{~A})$ and followed by incubation in microinjection buffer (B), Hank's medium (C), or Draq5 DNA dye (D) for $2 \mathrm{~h}$. After 3\% paraformaldehyde fixation, cells were stained with human anti-RR serum (green) and rabbit anti-IMPDH2 antibody (red). Nuclei were counterstained by DAPI (blue). Bar: 20 um. Figure S3. Stationary RR structures detected in live HeLa cells. (A) HeLa cells treated with $1 \mathrm{mM}$ ribavirin for $24 \mathrm{~h}$ were microinjected with Alexa 488-conjugated rabbit anti-IMPDH2 antibody. (B) HeLa cells transfected with IMPDH2-GFP were kept in medium containing $1 \mathrm{mM}$ ribavirin for $18 \mathrm{~h}$. Sequential pictures were captured from live cells and the images shown represent $2 \mathrm{~min}$ intervals for a total of $10 \mathrm{~min}$. Nuclei were stained with Draq5 (red). (C) IMPDH2-GFP and anti-IMPDH2 antibody (red) labeled the same RR in transfected HeLa cells (arrows). Nuclei were counterstained with DAPI (blue). Bars: $10 \mu \mathrm{m}$. Figure S4. Dose-dependent effect of Alexa 488-conjugated anti-IMPDH2 antibody microinjected correlated with the level of RR disassembly. COS-7 cells were microinjected for $0.2 \mathrm{~s}$ each $(n=30)$ or $2 \mathrm{~s}$ each $(n=25)$ and followed for $20 \mathrm{~min}$ to observe the percent of cells demonstrating disassembly of RR.

Additional file 2: Movie S1. Ribavirin-induced RR structures in live COS-7 cells remain mostly stationary. COS-7 cells treated with $1 \mathrm{mM}$ ribavirin for $24 \mathrm{~h}$ were microinjected with rabbit anti-IMPDH2 conjugated with Alexa 488 (green). After 10-15 min, sequential pictures were captured for $10 \mathrm{~min}$ at 10-second intervals. The video is a view of the pictures accelerated 100 times. Nucleus (red) was stained with Draq5.

Additional file 3: Movie S2. Disassembly of ribavirin-induced RR by the microinjection of anti-IMPDH2 antibody. COS-7 cells treated with $1 \mathrm{mM}$ ribavirin for $24 \mathrm{~h}$ were microinjected with rabbit anti-IMPDH2 conjugated with Alexa 488 (green). After 10-15 min, sequential pictures were captured for $10 \mathrm{~min}$ at 10 -second intervals. The video is a view of the pictures accelerated 100 times. RR structures are documented to disassemble into small fragments and some completely disappeared. Nucleus (red) was stained with Draq5.

Additional file 4: Movie S3. Disassembly of MPA-induced RR by the microinjection of anti-IMPDH2 antibody. COS-7 cells treated with $1 \mathrm{mM}$ MPA for $24 \mathrm{~h}$ were microinjected with rabbit anti-IMPDH2 conjugated with Alexa 488. After 10-15 min, sequential pictures were captured for $10 \mathrm{~min}$ at 10 -second intervals. The video is a view of the pictures accelerated 100 times. The rod was observed to break into pieces before complete disassembly. Nucleus (red) was stained with Draq5.

Additional file 5: Movie S4. RR in live COS-7 cells labeled by IMPDH2-GFP also show stationary behavior. After $18 \mathrm{~h}$ of IMPDH2-GFP transfection into COS-7 cells and $1 \mathrm{mM}$ ribavirin treatment, sequential pictures were captured for $10 \mathrm{~min}$ with 30-second intervals. The video is a view of the pictures accelerated 100 times. No obvious changes in size or shape of RR structure (green) were observed. Nucleus (red) was stained with Draq5.

\section{Abbreviations}

DAPI: 4',6-diamidino-2-phenylindole; DON: 6-Diazo-5-oxo-L-norleucine; EGFP: Enhanced green fluorescence protein; MPA: Mycophenolic acid; RR: Rods and rings.

\section{Competing interest}

The authors declare that they have no competing interests.

\section{Authors' contributions}

G.D.K. performed the experiments and participated in the writing of the manuscript; L.E.C.A. corrected the manuscript; S.S.G. designed and performed experiments and corrected the manuscript; E.K.L.C. designed experiments and wrote the manuscript. All authors read and approved the final manuscript.

\section{Acknowledgments}

We thank Dr. Daniel L. Purich, Department of Biochemistry \& Molecular Biology, for productive discussion. The generous help of S. John Calise in editing this work is greatly appreciated.

\section{Funding}

This work was supported by Brazilian government foundation CAPES (Coordenação de Aperfeiçoamento de Pessoal de Nível Superior) with process number 9028-11-0, and by São Paulo Government FAPESP (Fundação de Amparo a Pesquisa do Estado de São Paulo) with process number 2011/12448-0, both granted to G.D.K. and L.E.C.A.

\section{Author details}

'Department of Oral Biology, University of Florida, 1395 Center Drive, Gainesville, FL 32610-0424, USA. ${ }^{2}$ Rheumatology Division, Universidade Federal de São Paulo, Rua Botucatu 740, São Paulo, SP 04023-062, Brazil. ${ }^{3}$ Immunology Division, Fleury Medicine and Health Laboratories, Avenida Gal Waldomiro Lima 508, São Paulo, SP 04102-050, Brazil. ${ }^{4}$ Department of Biological Sciences, University of Idaho, 875 Center Drive, Moscow, ID 83844, USA.

Received: 25 July 2014 Accepted: 18 December 2014 Published: 5 January 2015

\section{References}

1. Carcamo WC, Calise SJ, von Muhlen CA, Satoh M, Chan EK. Molecular cell biology and immunobiology of mammalian rod/ring structures. Int Rev Cell Mol Biol. 2014;308:35-74.

2. Carcamo WC, Satoh M, Kasahara H, Terada N, Hamazaki T, Chan JY, et al. Induction of cytoplasmic rods and rings structures by inhibition of the CTP and GTP synthetic pathway in mammalian cells. PLoS One. 2011;6:e29690.

3. Thomas EC, Gunter JH, Webster JA, Schieber NL, Oorschot V, Parton RG, et al. Different characteristics and nucleotide binding properties of inosine monophosphate dehydrogenase (IMPDH) isoforms. PLoS One. 2012;7:e51096.

4. Liu JL. Intracellular compartmentation of CTP synthase in Drosophila. J Genet Genomics. 2010;37:281-96.

5. Azzam G, Liu JL. Only one isoform of Drosophila melanogaster CTP synthase forms the cytoophidium. PLoS Genet. 2013;9:e1003256.

6. O'Connell JD, Zhao A, Ellington AD, Marcotte EM. Dynamic reorganization of metabolic enzymes into intracellular bodies. Annu Rev Cell Dev Biol. 2012;28:89-111.

7. Barry RM, Bitbol AF, Lorestani A, Charles EJ, Habrian $\mathrm{CH}$, Hansen JM, et al. Large-scale filament formation inhibits the activity of CTP synthetase Elife. 2014:3:e03638.

8. Aughey GN, Grice SJ, Shen QJ, Xu Y, Chang CC, Azzam G, et al. Nucleotide synthesis is regulated by cytoophidium formation during neurodevelopment and adaptive metabolism. Biology open. 2014;3:1045-56.

9. Strochlic TI, Stavrides KP, Thomas SV, Nicolas E, O'Reilly AM, Peterson JR. Ack kinase regulates CTP synthase filaments during Drosophila oogenesis. EMBO Rep. 2014;15:1184-91.

10. Probst C, Radzimski C, Blocker IM, Teegen B, Bogdanos DP, Stocker W, et al. Development of a recombinant cell-based indirect immunofluorescence assay (RC-IFA) for the determination of autoantibodies against "rings and rods"-associated inosine-5'-monophosphate dehydrogenase 2 in viral hepatitis C. Clin Chim Acta. 2013;418:91-6.

11. Keppeke GD, Nunes E, Ferraz ML, Silva EA, Granato C, Chan EK, et al. Longitudinal study of a human drug-induced model of autoantibody to cytoplasmic rods/rings following HCV therapy with ribavirin and interferonalpha. PLoS One. 2012;7:e45392.

12. Covini G, Carcamo WC, Bredi E, von Muhlen CA, Colombo M, Chan EKL. Cytoplasmic rods and rings autoantibodies developed during pegylated interferon and ribavirin therapy in patients with chronic hepatitis C. Antivir Ther. 2012;17:805-11. 
13. Seelig HP, Appelhans $\mathrm{H}$, Bauer $\mathrm{O}$, Bluthner M, Hartung K, Schranz $\mathrm{P}$, et al. Autoantibodies against inosine-5'-monophosphate dehydrogenase 2-characteristics and prevalence in patients with HCV-infection. Clin Lab. 2011;57:753-65.

14. Keppeke GD, Satoh M, Ferraz ML, Chan EK, Andrade LE. Temporal evolution of human autoantibody response to cytoplasmic rods and rings structure during anti-HCV therapy with ribavirin and interferon-alpha. Immunol Res. 2014:60:38-49.

15. Stinton LM, Myers RP, Coffin CS, Fritzler MJ. Clinical associations and potential novel antigenic targets of autoantibodies directed against rods and rings in chronic hepatitis C infection. BMC Gastroenterol. 2013;13:50.

16. Balint S, Verdeny Vilanova I, Sandoval Alvarez A, Lakadamyali M. Correlative live-cell and superresolution microscopy reveals cargo transport dynamics at microtubule intersections. Proc Natl Acad Sci U S A. 2013;110:3375-80.

17. Orzech E, Livshits L, Leyt J, Okhrimenko H, Reich V, Cohen S, et al. Interactions between adaptor protein-1 of the clathrin coat and microtubules via type 1a microtubule-associated proteins. J Biol Chem. 2001;276:31340-8.

18. Ross JL, Ali MY, Warshaw DM. Cargo transport: molecular motors navigate a complex cytoskeleton. Curr Opin Cell Biol. 2008;20:41-7.

19. Shima DT, Cabrera-Poch N, Pepperkok R, Warren G. An ordered inheritance strategy for the Golgi apparatus: visualization of mitotic disassembly reveals a role for the mitotic spindle. J Cell Biol. 1998;141:955-66.

20. Li S, Lian SL, Moser JJ, Fritzler ML, Fritzler MJ, Satoh M, et al. Identification of GW182 and its novel isoform TNGW1 as translational repressors in Ago2-mediated silencing. J Cell Sci. 2008;121:4134-44.

21. Lian SL, Li S, Abadal GX, Pauley BA, Fritzler MJ, Chan EKL. The C-terminal half of human Ago2 binds to multiple GW-rich regions of GW182 and requires GW182 to mediate silencing. RNA. 2009;15:804-13.

22. Tramier M, Zahid M, Mevel JC, Masse MJ, Coppey-Moisan M. Sensitivity of CFP/YFP and GFP/mCherry pairs to donor photobleaching on FRET determination by fluorescence lifetime imaging microscopy in living cells. Microsc Res Tech. 2006;69:933-9.

23. Jockusch BM, Zurek B, Zahn R, Westmeyer A, Fuchtbauer A. Antibodies against vertebrate microfilament proteins in the analysis of cellular motility and adhesion. J Cell Sci Suppl. 1991;14:41-7.

24. Lamb NJ, Gauthier-Rouviere C, Fernandez A. Microinjection strategies for the study of mitogenic signaling in mammalian cells. Front Biosci. 1996;1: d19-29.

25. Benavente R, Krohne $G$. In vivo systems to study the dynamics of nuclear lamins. Methods Cell Biol. 1998;53:591-602.

26. Tolle HG, Weber K, Osborn M. Microinjection of monoclonal antibodies specific for one intermediate filament protein in cells containing multiple keratins allow insight into the composition of particular $10 \mathrm{~nm}$ filaments. Eur J Cell Biol. 1985;38:234-44.

27. Meyer T, Weber K, Osborn M. Microinjection of IFA antibody induces intermediate filament aggregates in epithelial cell lines but perinuclear coils in fibroblast-like lines. Eur J Cell Biol. 1992;57:75-87.

28. Carcamo WC, Ceribelli A, Calise SJ, Krueger C, Liu C, Daves M, et al. Differential reactivity to IMPDH2 by anti-rods/rings autoantibodies and unresponsiveness to pegylated interferon-alpha/ribavirin therapy in US and Italian HCV patients. J Clin Immunol. 2013;33:420-6.

29. Ellis RJ. Macromolecular crowding: an important but neglected aspect of the intracellular environment. Curr Opin Struct Biol. 2001;11:114-9.

30. Luby-Phelps K. Cytoarchitecture and physical properties of cytoplasm: volume, viscosity, diffusion, intracellular surface area. Int Rev Cytol. 2000;192:189-221.

31. Mannava S, Grachtchouk V, Wheeler LJ, Im M, Zhuang D, Slavina EG, et al. Direct role of nucleotide metabolism in C-MYC-dependent proliferation of melanoma cells. Cell Cycle. 2008;7:2392-400.

32. Ji Y, Gu J, Makhov AM, Griffith JD, Mitchell BS. Regulation of the interaction of inosine monophosphate dehydrogenase with mycophenolic Acid by GTP. J Biol Chem. 2006;281:206-12.

33. Calise SJ, Carcamo WC, Krueger C, Yin JD, Purich DL, Chan EK. Glutamine deprivation initiates reversible assembly of mammalian rods and rings. Cell Mol Life Sci. 2014;71:2963-73.

34. Collart FR, Chubb CB, Mirkin BL, Huberman E. Increased inosine-5'-phosphate dehydrogenase gene expression in solid tumor tissues and tumor cell lines. Cancer Res. 1992;52:5826-8

35. Jackson RC, Weber G, Morris HP. IMP dehydrogenase, an enzyme linked with proliferation and malignancy. Nature. 1975;256:331-3.
36. Gou KM, Chang CC, Shen QJ, Sung LY, Liu JL. CTP synthase forms cytoophidia in the cytoplasm and nucleus. Exp Cell Res. 2014;323:242-53.

37. Tolle HG, Weber $\mathrm{K}$, Osborn M. Microinjection of monoclonal antibodies to vimentin, desmin, and GFA in cells which contain more than one IF type. Exp Cell Res. 1986;162:462-74.

38. Thyberg J, Moskalewski S. Role of microtubules in the organization of the Golgi complex. Exp Cell Res. 1999;246:263-79.

39. Vaisberg EA, Grissom PM, McIntosh JR. Mammalian cells express three distinct dynein heavy chains that are localized to different cytoplasmic organelles. J Cell Biol. 1996;133:831-42.

40. Morgan DO, Roth RA. Analysis of intracellular protein function by antibody injection. Immunol Today. 1988;9:84-8.

41. Lee GM. Measurement of volume injected into individual cells by quantitative fluorescence microscopy. J Cell Sci. 1989;94(Pt 3):443-7.

42. Minaschek G, Bereiter-Hahn J, Bertholdt G. Quantitation of the volume of liquid injected into cells by means of pressure. Exp Cell Res. 1989;183:434-42.

43. Furuta K, Chan EKL, Kiyosawa K, Reimer G, Luderschmidt C, Tan EM. Heterochromatin protein HP1Hsbeta (p25beta) and its localization with centromeres in mitosis. Chromosoma. 1997;106:11-9.

44. Jakymiw A, Ikeda K, Fritzler MJ, Reeves WH, Satoh M, Chan EKL. Autoimmune targeting of key components of RNA interference. Arthritis Res Ther. 2006:8:R87.

doi:10.1186/2045-3701-5-1

Cite this article as: Keppeke et al:: Microinjection of specific anti-IMPDH2 antibodies induces disassembly of cytoplasmic rods/rings that are primarily stationary and stable structures. Cell \& Bioscience 2015 5:1.

\section{Submit your next manuscript to BioMed Central and take full advantage of:}

- Convenient online submission

- Thorough peer review

- No space constraints or color figure charges

- Immediate publication on acceptance

- Inclusion in PubMed, CAS, Scopus and Google Scholar

- Research which is freely available for redistribution 